\title{
Facile Synthesis of Polyethylene Glycol@Tannin-Amine Microsphere towards Cr(VI) Removal
}

\author{
Chengbing Yuan, Yan Zhang, Jinshui Yao, Qinze Liu * and Fan-Gong Kong *
}

check for updates

Citation: Yuan, C.; Zhang, Y.; Yao, J.; Liu, Q.; Kong, F.-G. Facile Synthesis of Polyethylene

Glycol@Tannin-Amine Microsphere towards Cr(VI) Removal. Polymers 2021, 13, 1035. https://doi.org/ $10.3390 /$ polym 13071035

Academic Editor: Piotr Cyganowski

Received: 4 March 2021

Accepted: 22 March 2021

Published: 26 March 2021

Publisher's Note: MDPI stays neutral with regard to jurisdictional claims in published maps and institutional affiliations.

Copyright: (c) 2021 by the authors. Licensee MDPI, Basel, Switzerland. This article is an open access article distributed under the terms and conditions of the Creative Commons Attribution (CC BY) license (https:// creativecommons.org/licenses/by/ $4.0 /)$.
State Key Laboratory of Biobased Material and Green Papermaking, School of Materials Science and Engineering, Qilu University of Technology (Shandong Academy of Sciences), Jinan 250353, China; sdnyycb@126.com (C.Y.); 17864181164@163.com (Y.Z.); yaojsh@qlu.edu.cn (J.Y.)

* Correspondence: liuqinze@qlu.edu.cn (Q.L.); kfg@qlu.edu.cn (F.-G.K.)

Abstract: Herein, a synthetic strategy for a rough microsphere $\mathrm{Cr}(\mathrm{VI})$-adsorbent via the reaction of tannic acid (TA) and 1,6-hexanediamine (HA) and using polyethylene glycol (PEG) as surface modifier was presented. This adsorbent was characterized by a Fourier Transform Infrared spectrometer (FTIR), thermogravimetic analysis (TGA), X-ray photoelectron spectroscopy (XPS), etc. Certain factors, including contact time, PEG@poly(tannin-1,6-hexanediamine) (PEG@PTHA) dosage, initial concentration, and experimental temperature affecting the $\mathrm{Cr}(\mathrm{VI})$ adsorption performance of adsorbent were explored. PEG@PTHA can adsorb $\mathrm{Cr}$ and the $\mathrm{Cr}(\mathrm{VI})$ was reduced up to $\mathrm{Cr}(\mathrm{III})$ due to the existence of phenolic hydroxyl groups. Its adsorption capacity can reach up to $300 \mathrm{mg} / \mathrm{g}$ within $10 \mathrm{~min}$ and approximately $100 \%$ removal percentage below the initial concentration of $100 \mathrm{mg} / \mathrm{L}$. Its behavior matched well with the Langmuir isotherm model and pseudo-second-order kinetic model. A PEG@PTHA adsorbent with maximum adsorption capacity $(450 \mathrm{mg} / \mathrm{g})$ has great prospects in $\mathrm{Cr}(\mathrm{VI})$-sewage treatment.

Keywords: tannin-amine composite; polyethylene glycol; $\mathrm{Cr}(\mathrm{VI})$ removal

\section{Introduction}

$\mathrm{Cr}(\mathrm{VI})$ poses an enormous threat to human health due to its high carcinogenicity; $\mathrm{Cr}(\mathrm{VI})$ was produced in the industrial production of leather tanning, textile dyeing. In view of its high toxicity and refractory degradability in solution, it poses a huge threat to human health [1-3]. Cr generally exists in two valence states: trivalent and hexavalent [4]. $\mathrm{Cr}$ (III) is an essential element for human growth. In order to meet the emission standard $(0.05-0.1 \mathrm{mg} / \mathrm{L})$, many methods including membrane separation, advanced oxidation, biological treatment, and ozone treatment were used to remove or reduce $\mathrm{Cr}(\mathrm{VI})$ [5]. Based on the limitations of the above-mentioned methods (high cost, low adsorption efficiency, and poor operability), more suitable routes need to be explored urgently.

Comparing with photocatalytic degradation [6], oxidation-reduction, and coprecipitation $[5,7,8]$, adsorption is regarded as a promising water treatment method in view of its low energy consumption and easy operation $[9,10]$. The development of cheap and efficient adsorbent has become the top priority in the industry, which is directly related to its practical application. So far, various novel adsorbents have been reported, for example, inorganic adsorbents including activated carbon and graphene have some disadvantages of low removal capacity and poor selectivity [11,12]. As for the organic adsorbent including fluorescent chitosan-based hydrogel and epichlorohydrin crosslinked polyethylenimine-chitin adsorbent, the complexity of the preparation process limits their wide application $[13,14]$. Hence facile preparation and low cost are considered as key factors for the design of $\mathrm{Cr}(\mathrm{VI})$-adsorbent.

Tannic acid (TA) is a natural polyphenolic compound widely found in various plants [15]. The catechol groups present in TA react with primary amine groups to form a new type of macromolecular structure polymer, and it is rich in phenolic hydroxyl $(\mathrm{ph}-\mathrm{OH})$ and 
$-\mathrm{NH}_{2}$ groups, which provides a new idea for the design of new adsorbents [16,17]. Liu et al. prepared a polytannin-1,6-hexamethylenediamine adsorbent with an adsorption capacity of $200 \mathrm{mg} / \mathrm{g}$ to remove $\mathrm{Cr}(\mathrm{VI})$ [18]. In addition, polyethylene glycol (PEG) has the advantage of easy solubility and has great potential for removing $\mathrm{Cr}(\mathrm{VI})$ [19].

In this work, a tannin-amine microsphere was fabricated via an environmentally friendly and straightforward preparation method with the help of polyethylene glycol (PEG) [17]. PEG, a potential Cr(VI)-adsorbent, can be mixed in a tannin-amine system to form rough porous microspheres and increase the rate and amount of adsorption [20]. Various characterization methods were selected to evaluate structural performance and adsorption capacity, and adsorption experiments were conducted sequentially. Besides, the adsorption model including kinetics, isotherms, and thermodynamics were further studied in the following.

\section{Experimental Section}

\subsection{Materials}

Poly(ethylene glycol) (PEG, AR) and Potassium dichromate $\left(\mathrm{K}_{2} \mathrm{Cr}_{2} \mathrm{O}_{7}, \mathrm{AR}\right)$ were purchased from Maclean, Tannic acid (TA, AR) and 1,6-hexanediamine (HA, AR) were supported by Aladdin. The ultrapure water (UW $18.25 \mathrm{M} \Omega \mathrm{cm}$ ) was utilized in the following experiments.

\subsection{General Characterization}

Thermogravimetric analysis (TGA, TGA-1, Mettler Toledo, Columbus, OH, USA) was used to investigate the difference in the thermal stability of temperature range of $45-800{ }^{\circ} \mathrm{C}$ $\left(10^{\circ} \mathrm{C} / \mathrm{min}\right)$. A Fourier transform infrared spectrometer (FT-IR, Thermo Nicolet, Waltham, MA, USA) was used to investigate the characteristic chemical bonds of materials. Microtopography and element content were examined with a scanning electron microscope (SEM, Quanta 200, Hillsboro, OR, USA) and an energy dispersive spectrometer (EDS, Quanta 200, Hillsboro, OR, USA). X-ray photoelectron spectroscopy (XPS, Thermon Scientific, Waltham, MA, USA) was used to investigate the change of elements. An ultraviolet spectrophotometer (UV, UV-2550, Tokyo, Japan) was used to investigate the actual concentration of $\mathrm{Cr}(\mathrm{VI})$ solution.

\subsection{Preparation of PEG@PTHA}

By adjusting the PEG/TA weight ratio and fixing the HA/TA mole ratio (12.5:1), four microsphere adsorbents were fabricated at room temperature including 0:1 (0-PEG@PTHA), 0.5:1 (PEG@PTHA), 1:1 (1-PEG@PTHA), and 2:1 (2-PEG@PTHA). Taking PEG@PTHA as an example, (1) $0.5 \mathrm{~g}$ PEG and $0.85 \mathrm{~g}$ HA were added into $50 \mathrm{~mL} \mathrm{UW}$ and then ultra-sounded to disperse evenly; (2) $1.0 \mathrm{~g}$ TA was charged into $50 \mathrm{~mL}$ UW and dispersed uniformly; (3) the mixture of PEG and HA was added into the above TA solution by drop. The sediment was separated and alternately washed with UW and ethanol absolute three times. The resultant PEG@PTHA composite was finally dried via freeze-drying for next use. The preparation process of PEG@PTHA and its possible reaction mechanism can be seen in Figure 1.

\subsection{Adsorption Experiment}

All concentrations of the solution used were diluted from a pre-prepared high concentration solution $(2000 \mathrm{mg} / \mathrm{L})$, and the $\mathrm{pH}$ value was regulated by $\mathrm{HCl}(1 \mathrm{~mol} / \mathrm{L})$ and $\mathrm{NaOH}(1 \mathrm{~mol} / \mathrm{L})$. Experiments were executed to explore the effects of significant parameter concluding contact time ( $0-24 \mathrm{~h}), \mathrm{pH}$ value $(2-7)$, initial concentration $(60-160 \mathrm{mg} / \mathrm{L})$, and temperature. For this purpose, $100 \mathrm{~mL}$ of $\mathrm{Cr}(\mathrm{VI})$ solution was taken in a $200 \mathrm{~mL}$ grinding mouth bottle with a certain amount of adsorbent. The bottles were put into a shaker for $24 \mathrm{~h}$ or $48 \mathrm{~h}$. The concentration of $\mathrm{Cr}(\mathrm{VI})$ solution was measured by $\mathrm{UV}$ instrument according to the 1,5-diphenylcarbazide method. 


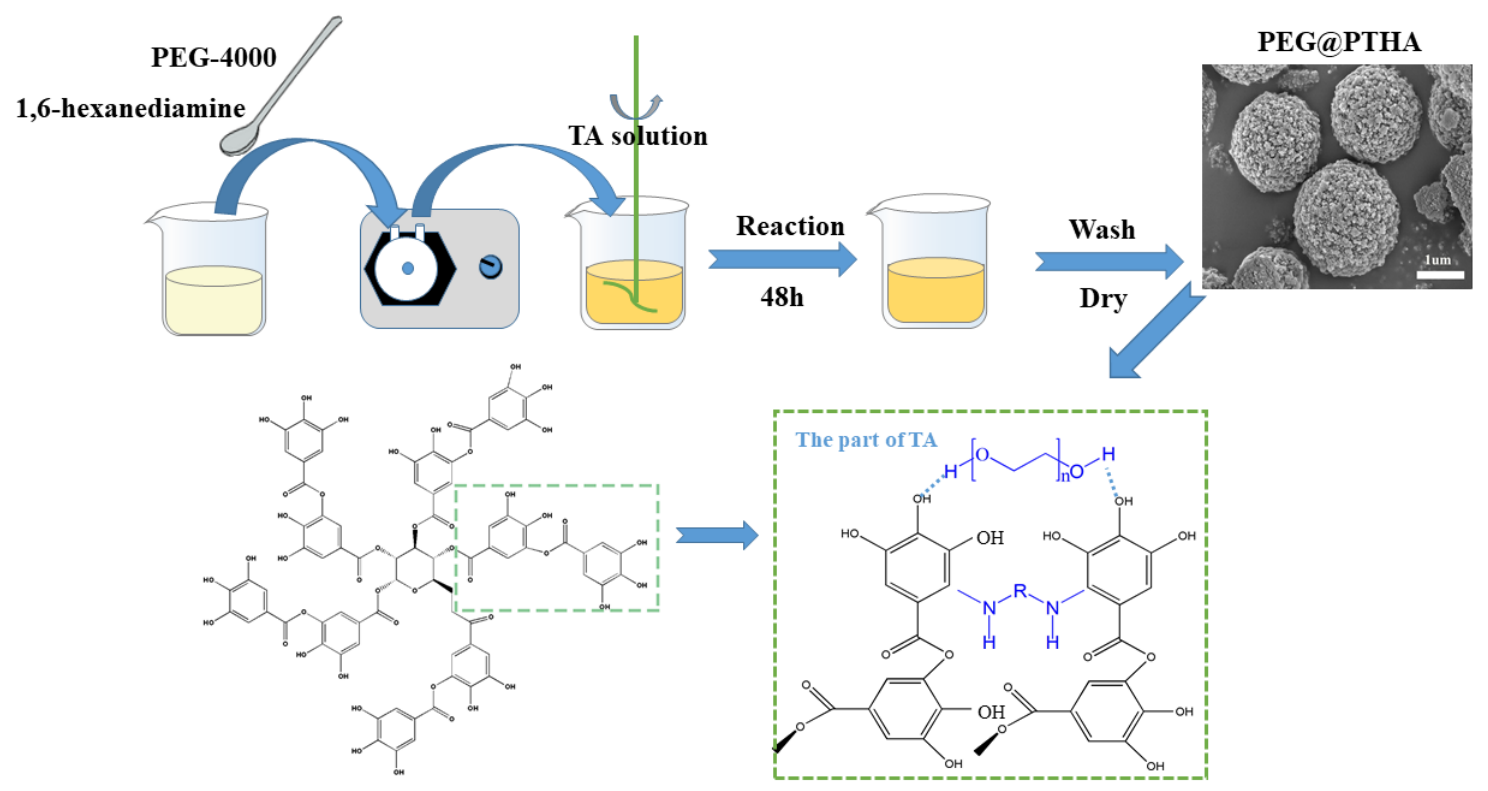

Figure 1. Schematic diagram of preparation procedure and possible preparation mechanism of the PEG@PTHA composite adsorbent.

The adsorption behavior of the adsorbent was evaluated with the following Equations (1) and (2):

$$
q_{t}=\left(C_{0}-C_{t}\right) V / m
$$

where $q_{t}(\mathrm{mg} / \mathrm{g})$ is the adsorption capacity at contact time $t(\mathrm{~s}) ; q_{e}(\mathrm{mg} / \mathrm{g})$ can be obtained at equilibrium time; $C_{0}(\mathrm{mg} / \mathrm{L})$ and $C_{t}(\mathrm{mg} / \mathrm{L})$ are the initial and real-time concentrations, respectively; $V(\mathrm{~L})$ is the simulated wastewater volume; and $m(\mathrm{~g})$ represents the weight of PEG@PTHA.

$$
R \%=\left(C_{0}-C_{e}\right) / C_{0} \times 100 \%
$$

where $R(\%)$ is the removal rate; and $C_{0}(\mathrm{mg} / \mathrm{L})$ and $C_{e}(\mathrm{mg} / \mathrm{L})$ are the initial and equilibrium concentrations of $\mathrm{Cr}(\mathrm{VI})$, respectively.

\section{Results and Discussion}

\subsection{SEM-EDS Characteristic}

The difference between 0-PEG@PTHA and PEG@PTHA in morphology is shown in Figure 2a,b. The surface of PEG@PTHA is much rougher than that of 0-PEG@PTHA, which can be due to the presence of PEG. Its high dissolubility and leaving of the PEG-PTHA system cause the existence of this rough surface (Figure 2c). The EDX image of PEG@PTHA after loading $\mathrm{Cr}(\mathrm{VI})$ is presented in Figure 2d. In addition to $\mathrm{C}, \mathrm{N}$, and $\mathrm{O}$, there were $\mathrm{Cr}$ elements loaded on the adsorbent surface. It can be concluded that $\mathrm{Cr}$ distributed evenly over the surface of the adsorbent.

\subsection{FT-IR Characteristic}

The FT-IR spectrum of PTHA and PEG@PTHA can be seen in Figure 3a. The peak at $1080-1150 \mathrm{~cm}^{-1}$, which was attributed to stretching vibration of $\mathrm{C}-\mathrm{O}-\mathrm{C}$ in $\mathrm{PEG}$, can be found at 1035-1140 $\mathrm{cm}^{-1}$ in PEG@PTHA, the peaks at 2840 and $2940 \mathrm{~cm}^{-1}$ were attributed to the stretching vibration of $\mathrm{C}-\mathrm{H}$ in $\mathrm{HA}$, there were two small adsorption peaks in the same range in PEG@PTHA. The wide characteristic peak at 3550-3200 $\mathrm{cm}^{-1}$ resulted from the stretching vibration of $\mathrm{O}-\mathrm{H}$ in TA and $-\mathrm{NH}$ in $\mathrm{HA}$. The stretching vibration of $\mathrm{C}=\mathrm{O}$ and the benzene ring in PEG@PTHA were located at 1710 and $1600 \mathrm{~cm}^{-1}$, respectively. PEG was attached successfully to the surface of PTHA microspheres and they combined well with each other. As can be seen in Figure $3 b$, the peak at $540 \mathrm{~cm}^{-1}$ was attributed to 
the vibration of $\mathrm{Cr}=\mathrm{O}$, and the peaks at 919 and $809 \mathrm{~cm}^{-1}$ were attributed to the phenolic hydroxyl group that interacts with $\mathrm{Cr}$ [21].

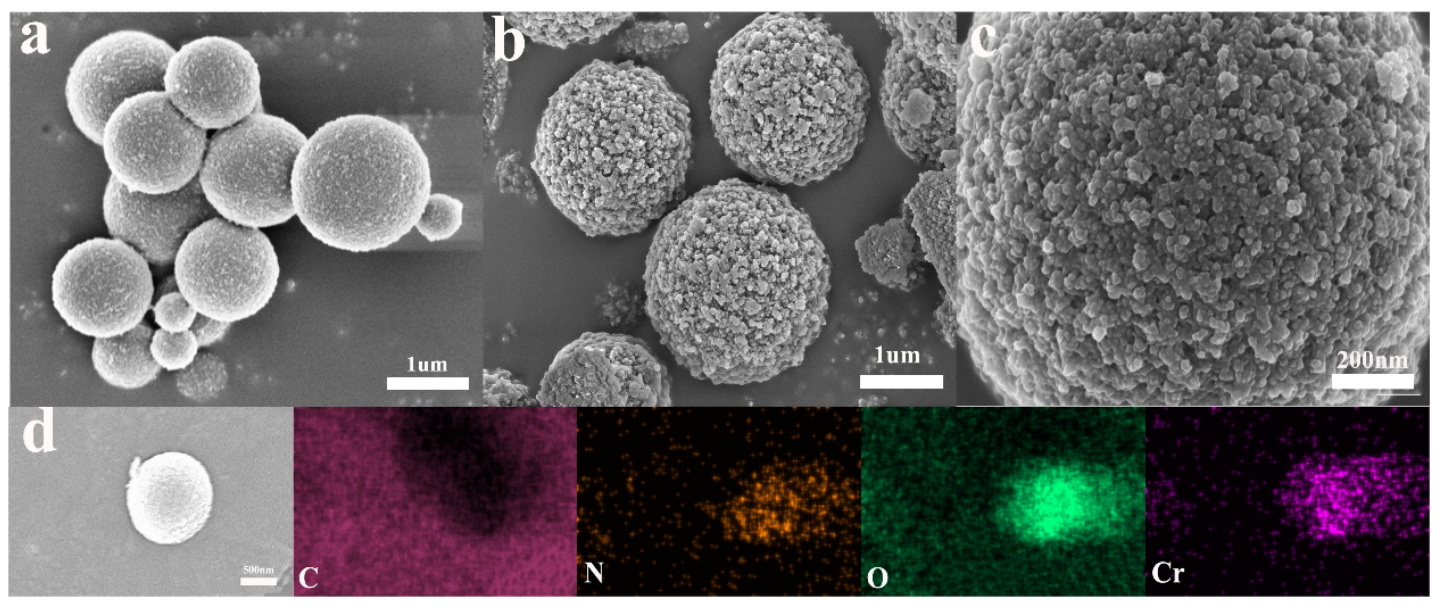

Figure 2. (a) SEM image of PTHA, (b) SEM image PEG@PTHA, (c) partial enlarged SEM image of PEG@PTHA, (d) EDS image of used PEG@PTHA.
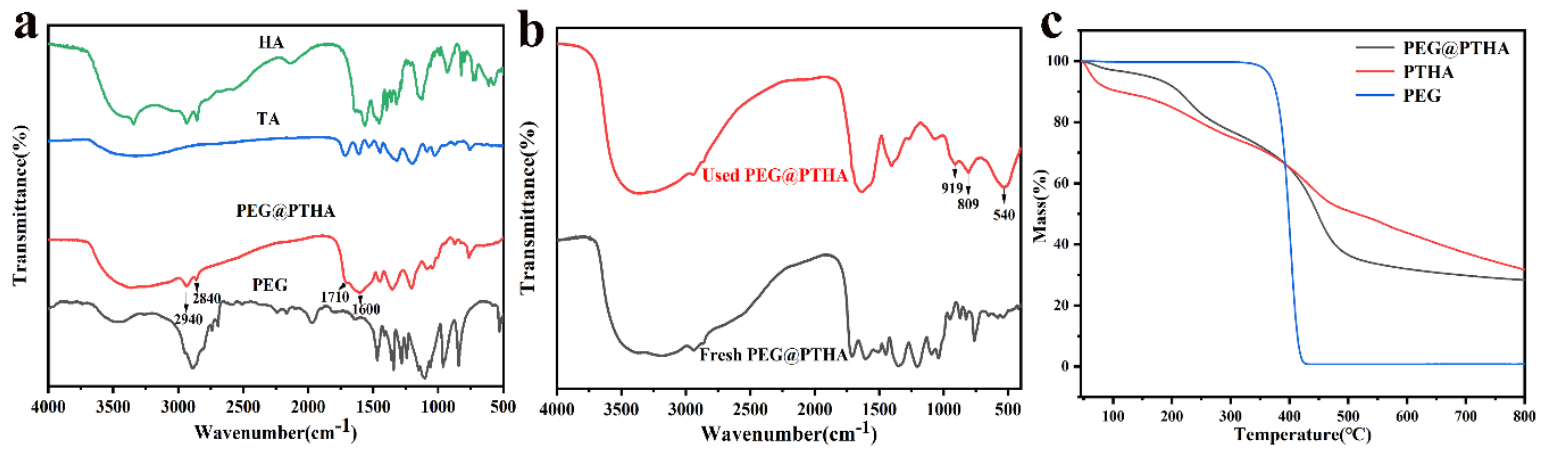

Figure 3. (a) FTIR spectrogram of HA, TA PEG, and PEG@PTHA, (b) FT-IR spectrogram of Fresh PEG@PTHA and used PEG@PTHA, (c) TGA curve of PEG@PTHA, PTHA, and PEG.

\subsection{TGA Analysis}

The thermal performances of PTHA and PEG@PTHA were investigated by using heat constantly from $45-800{ }^{\circ} \mathrm{C}$ in the $\mathrm{N}_{2}$ atmosphere $(10 \mathrm{k} / \mathrm{min})$. The downtrend of PTHA and PEG@PTHA before $150{ }^{\circ} \mathrm{C}$ was attributed to the weight loss of the combined water. The thermostability of PEG@PTHA was better than PTHA before $400^{\circ} \mathrm{C}$, however, due to the molecular chain of PEG being broken at $400{ }^{\circ} \mathrm{C}$, the heat resistance of PTHA was better after $400{ }^{\circ} \mathrm{C}$, which also confirmed the presence of PEG (Figure 3c).

\subsection{Effect of Contact Time}

As can be seen in Figure 4a, the adsorption capacity increases with the extension of contact time, the adsorption capacity can reach up to $200 \mathrm{mg} / \mathrm{g}$ after $10 \mathrm{~min}$. On account of the decrease of the adsorption active site, the removal rate of $Q_{t}$ slowed down, the equilibrium was basically reached at $24 \mathrm{~h}$. In view of this situation, we selected $24 \mathrm{~h}$ as the contact time in the subsequent adsorption experiments. The fast adsorption capacity of PEG@PTHA is shown in Figure 4b. PEG@PTHA achieved an almost 100\% removal percentage much sooner compared to the pure PTHA adsorbent under the same experimental conditions $\left(100 \mathrm{~mL}, 100 \mathrm{mg} / \mathrm{L}, 30^{\circ} \mathrm{C}\right)$. The reason for this phenomenon is due to the existence of the rough surface of PEG@PTHA, which can increase the chance of contact between the active site and chromium ions, thus possessing a faster removal property. 

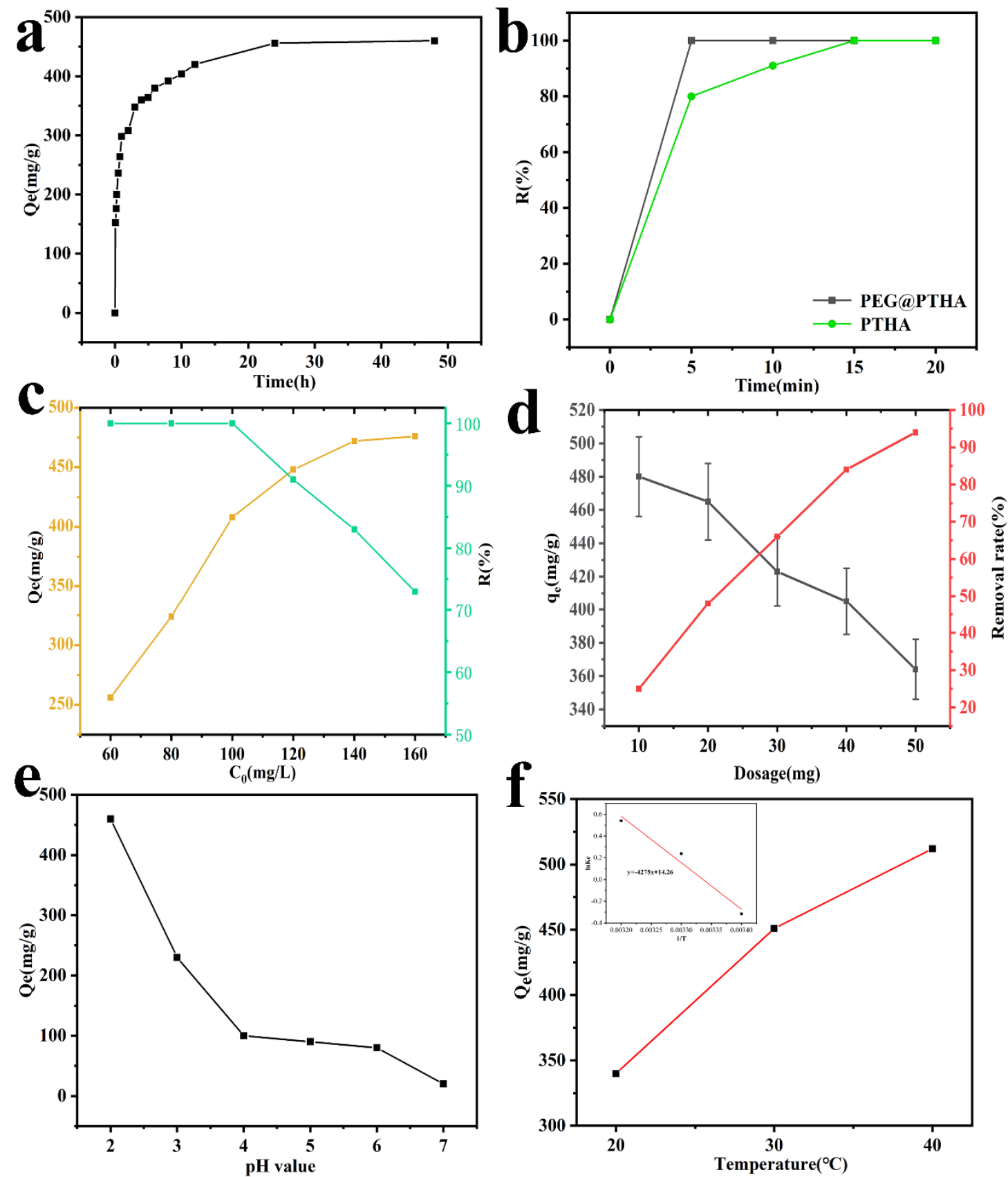

Figure 4. (a) effects of contact time $\left(0-48 \mathrm{~h}, \mathrm{C}_{0}=200 \mathrm{mg} / \mathrm{L}, \mathrm{T}=303 \mathrm{~K}\right.$, dos $\left.=25 \mathrm{mg}, \mathrm{V}=100 \mathrm{~mL}, \mathrm{pH}=2\right)$, (b) the difference of removal rate between PTHA and PEG@PTHA $\left(C_{0}=60 \mathrm{mg} / \mathrm{L}, \mathrm{pH}=2, \mathrm{~T}=303 \mathrm{~K}, \mathrm{dos}=25 \mathrm{mg}, \mathrm{V}=100 \mathrm{~mL}\right)$, (c) effect of initial concentration $\left(C_{0}=60-160 \mathrm{mg} / \mathrm{L}, \mathrm{T}=303 \mathrm{~K}\right.$, dos $\left.=25 \mathrm{mg}, \mathrm{t}=24 \mathrm{~h}, \mathrm{~V}=100 \mathrm{~mL}\right)$, (d) effect of different adsorbent dosage $\left(10-50 \mathrm{mg}, \mathrm{C}_{0}=200 \mathrm{mg} / \mathrm{L}, \mathrm{T}=303 \mathrm{~K}, \mathrm{~V}=100 \mathrm{~mL}, \mathrm{pH}=2\right)$, (e) effect of $\mathrm{PH}$ value $\left(C_{0}=200 \mathrm{mg} / \mathrm{L}, \mathrm{T}=303 \mathrm{~K}, \mathrm{dos}=25 \mathrm{mg}\right.$, $\mathrm{V}=100 \mathrm{~mL}, \mathrm{t}=24 \mathrm{~h})$, (f) effect of different environmental temperature $\left(C_{0}=200 \mathrm{mg} / \mathrm{L}, \operatorname{dos}=25 \mathrm{mg}, \mathrm{V}=100 \mathrm{~mL}, \mathrm{t}=24 \mathrm{~h}\right)$.

\subsection{Effect of Initial Concentration}

The comparison of different $\mathrm{Cr}(\mathrm{VI})$ concentrations $(60-160 \mathrm{mg} / \mathrm{L})$ is presented in Figure 4c. It can be concluded that the adsorption capacity of PEG@PTHA enhanced with the increase of ion concentration. While the initial concentration was less than $100 \mathrm{mg} / \mathrm{L}$, the removal percentage of $\mathrm{Cr}(\mathrm{VI})$ can reach up to nearly $100 \%$, which is owed to the strong interaction between amino and carboxyl groups in PEG@PTHA and $\mathrm{Cr}(\mathrm{VI})$. The decrease in the removal percentage and the increase in the adsorption amount can be discovered as the initial concentration condensed. 


\subsection{Effect of Different Adsorbent Dosage}

As shown in Figure 4d, the effect of different PEG@PTHA dosages was studied, it revealed the relationship between adsorbent dosage and removal amount. With the increase of PEG@PTHA dosage, the removal amount decreased from $480 \mathrm{mg} / \mathrm{g}$ to $360 \mathrm{mg} /$ for a constant concentration of the $\mathrm{Cr}(\mathrm{VI})$ solution. When the amount of PEG@PTHA microspheres increases, the removal amount (or percentage) increases in the meanwhile. Yet, the adsorption capacity per unit mass of PEG@PTHA decreased and the utilization of PEG@PTHA became greatly lower.

\subsection{Effect of $\mathrm{pH}$ Value}

On account of the influence of $\mathrm{pH}$ value on the surface functional group state of PEG@PTHA, it was significant for Cr-removal to control the $\mathrm{pH}$ of the aqueous solution. The adsorption capacity decreases gradually with the enhancement of $\mathrm{pH}$ value, in the aqueous solution of $\mathrm{pH}=2-6, \mathrm{Cr}$ ions existed primarily in the form of $\mathrm{HCrO}_{4}{ }^{-}$. The capacity to adsorb $\mathrm{HCrO}_{4}{ }^{-}$can be enhanced by the protonation of $-\mathrm{OH}$ and $-\mathrm{NH}_{2}$ groups to $-\mathrm{OH}_{2}{ }^{+}$and $-\mathrm{NH}_{3}{ }^{+}$. With the increase of $\mathrm{pH}$, the degree of protonation goes down, resulting in the attenuation of adsorption capacity.

\subsection{Adsorption Isotherm Analysis}

The adsorption isotherm model is a significant technology that can be used to speculate the adsorption behavior of the adsorption isotherm model is appropriate for single-layer adsorption that occurs on a completely uniform surface. The equation is as follows:

Langmuir model

$$
C_{e} / Q_{e}=1 /\left(K_{L} Q_{m}\right)+C_{e} / Q_{e}
$$

in which $Q_{m}(\mathrm{mg} / \mathrm{g}), Q_{e}(\mathrm{mg} / \mathrm{g})$, and $C_{e}(\mathrm{mg} / \mathrm{L})$ represent maximum adsorption capacity, actual capacity, and residual concentration of $\mathrm{Cr}(\mathrm{VI})$, respectively. $K_{L}(\mathrm{~L} / \mathrm{mg})$ is the adsorption equilibrium factor for site affinity.

Freundlich's adsorption model assumes that the adsorbate reacts on the nonuniform surface by multi-layer adsorption, which indicates that the combined site is inequitable and co-dependent. The equation is as follows:

Freundlich model

$$
\log Q_{e}=\log K_{F}+1 / n \log C_{e}
$$

in which $K_{F}((\mathrm{mg} / \mathrm{g}) /(\mathrm{mg} / \mathrm{L}))$ and $1 / n$ are the Freundlich factors of adsorption capacity and adsorption strength, the numerical value of $n$ shows the advantage of adsorption. The Langmuir and Freundlich models were used to fit the experimental data. Judging from the correlation coefficient, the $\mathrm{R}^{2}$ in the Langmuir adsorption isotherm model can better fit the experimental data, and the calculated $Q_{m}$ is more consistent with the experimental data in Table 1.

Table 1. The parameters of isotherm models for removal of Cr by PEG@PTHA.

\begin{tabular}{ccccccc}
\hline & \multicolumn{3}{c}{ Langmuir Isotherm Model } & \multicolumn{3}{c}{ Freundlich Isotherm Model } \\
\hline Adsorbate & $\boldsymbol{K}_{L}(\mathbf{L} / \mathbf{m g})$ & $\boldsymbol{q}_{m}(\mathbf{m g} / \mathbf{g})$ & $\mathbf{R}^{2}$ & $K_{F}(\mathbf{m g} / \mathbf{g}) /(\mathbf{m g} / \mathbf{L})^{1 / \mathbf{n}}$ & $\mathbf{1 / n}$ & $\mathbf{R}^{\mathbf{n}}$ \\
Cr(VI) & 1.08 & 362 & 0.99393 & 197 & 0.23169 & 0.90842 \\
\hline
\end{tabular}

\subsection{Adsorption Kinetic Model}

So as to explore the kinetic mechanism of the adsorption process, the conventional kinetic model is used to analyze experimental data, Lagergren's pseudo-first-order and pseudo-second-order models can be used to describe this adsorption process.

Lagergren pseudo-first-order

$$
\log \left(q_{e}-q_{t}\right)=\log q_{e}-k_{1} t / 2.303
$$


Lagergren pseudo-second-order

$$
t / q_{t}=1 /\left(k_{2} q_{e}^{2}\right)+t / q_{e}
$$

Therein, $k_{1}(1 / \mathrm{min})$ and $k_{2}(\mathrm{~g} / \mathrm{mg} \mathrm{min})$ respectively correspond to the adsorption rate constant of Lagergren's pseudo-first-order and Lagergren pseudo-second-order. The $Q_{m}$ and $Q_{t}$ correspond to the adsorption capacity of equilibrium and any sampling time, respectively. The rate constant is applied to analyze the adsorption mechanism.

The values of $Q_{e}, k_{1}, k_{2}$, and $\mathrm{R}^{2}$ are listed in Table 2, the Lagergren pseudo-secondorder possesses higher $\mathrm{R}_{2}$, which can better describe the kinetics of $\mathrm{Cr}(\mathrm{VI})$ removal by PEG@PTHA.

Table 2. The parameters of the kinetic models for removal of Cr by PEG@PTHA.

\begin{tabular}{ccccccc}
\hline & \multicolumn{2}{c}{ Pseudo-First-Order } & \multicolumn{3}{c}{ Pseudo-Second-Order } \\
\hline Adsorbate & $\left.K_{\mathbf{1}} \mathbf{h}^{-\mathbf{1}}\right)$ & $\boldsymbol{q}_{e}(\mathbf{m g} / \mathbf{g})$ & $\mathbf{R}^{\mathbf{2}}$ & $K_{\mathbf{2}}\left(\mathbf{m} / \mathbf{m g ~ h}^{-\mathbf{1}}\right)$ & $\boldsymbol{q}_{e}(\mathbf{m g} / \mathbf{g})$ & $\mathbf{R}^{\mathbf{2}}$ \\
Cr(VI) & 0.00279 & 229 & 0.97335 & 0.0000544 & 458 & 0.99293 \\
\hline
\end{tabular}

\subsection{Intra-Particle Diffusion Model}

We explained the importance of diffusion toward adsorption through an intra-particle diffusion model. The Weber-Morris equation is as follows:

$$
q_{t}=K_{i d} t^{1 / 2}+C
$$

where $K_{i d}$ represents the intra-particle diffusion speed constant, and $C$ represents the boundary diffusion effect. The linear fitting equation of the diffusion in the particle can be obtained via the linear fitting of $t^{1 / 2}$ and $q_{t}$. The fitting result can be seen in Figure $5 \mathrm{~b}$. It displayed three discrete lines, which suggested that the adsorption process was operated by various procedures. $K_{i d}$ was particularly large in the first section and revealed a sharp interaction in the second section. The line fitting began to level off. This phenomenon is different from the developmental trend of the first stage The decrease in $K_{i d}$ indicates the drop in the severity of adsorption. The gentle phenomenon of the third section indicates the ending of adsorption. When the concentration of the target solution reduced and the diffusion rate slowed down, an equilibrium was attained at the end.

\subsection{Thermodynamic Study}

Temperature will affect the adsorption rate and physical structure of the PEG@PTHA on the target pollutant. On the basis of the change in temperature, the adsorption thermodynamics can provide information about the thermal properties and spontaneity of the removal process of $\mathrm{Cr}(\mathrm{VI})$ in the simulated sewage.

The relationship equation of the thermodynamic constants $\Delta G$ (Gibbs free energy), $\Delta H$ (standard enthalpy change), and $\Delta S$ (standard entropy change) is as follows:

$$
\begin{gathered}
\Delta G=\Delta H-T \cdot \Delta S \\
K_{\mathrm{c}}=C_{a} / C_{e}=\left(C_{0}-C_{e}\right) / C_{e}
\end{gathered}
$$

where $C_{a}(\mathrm{mg} / \mathrm{L})$ represents the amount of $\mathrm{Cr}(\mathrm{VI})$ adsorbed on the PEG@PTHA, and $C_{e}$ $(\mathrm{mg} / \mathrm{L})$ represents the concentration of the residual CR in solution.

The following is the Van Hoff equation:

$$
\ln K_{c}=-\Delta H / R T+\Delta S R
$$

where $\Delta G$ can be determined by using Equation (7) according to the fitting of a linear equation to calculate the $\Delta H$ and $\Delta S$ concrete numerical value (Figure 4e). As can be seen in Table 3, the value of $\Delta G$ was negative, which demonstrated the feasibility and 
spontaneity of the adsorption process, the value of $\Delta H$ was positive, which indicated that the adsorption process was endothermic, and $\Delta S>0$ revealed that the degree of chaos in the adsorption process increased.
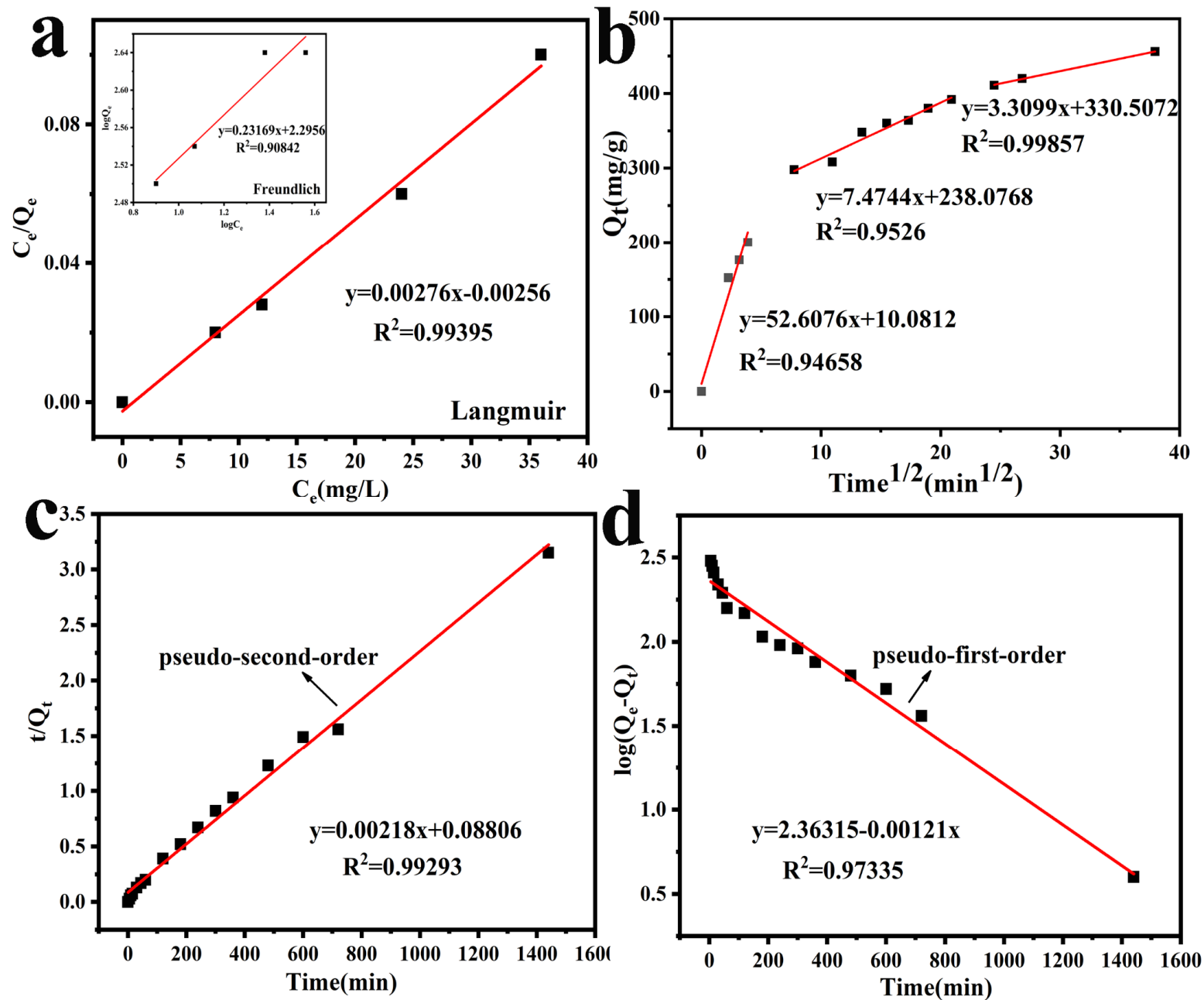

Figure 5. (a) Langmuir isotherm model and Freundlich isotherm model, (b) The intra-particle diffusion model, (c) Pseudosecond-order model, (d) Pseudo-first-order model.

Table 3. Thermodynamic Parameters of Cr(VI) Adsorption on PEG@PTHA microsphere.

\begin{tabular}{cccc}
\hline Temperature $(\mathrm{K})$ & $\Delta G(\mathrm{KJ} / \mathrm{mol})$ & $\Delta \boldsymbol{H}(\mathrm{KJ} / \mathrm{mol})$ & $\Delta S(\mathrm{~J} / \mathrm{molK})$ \\
\hline 293 & -1.36 & & \\
303 & -2.56 & 35.5 & 1.68 \\
313 & -4.17 & & \\
\hline
\end{tabular}

\subsection{Effect of Competing Ions}

The presence of co-existing ions can affect the adsorption capacity obviously, as can be seen in Figure 6. The addition of $\mathrm{NO}_{3}{ }^{-}$and $\mathrm{SO}_{4}{ }^{2-}$ decreased the value of $Q_{e}$, in other words, the adsorption capacity decreased with the interference of both of them. Further increasing the proportion of investment, the value of $Q_{e}$ changed less. Comparing with the weak electrostatic force between the active site and $\mathrm{HCrO}_{4}{ }^{-}, \mathrm{SO}_{4}{ }^{2-}$ had a clear competitive advantage, comparatively, the addition of $\mathrm{NO}_{3}{ }^{-}$did not have an excessive effect due to its weak competition. 


\subsection{XPS Analysis and Conjectural Adsorption Mechanism}

As is shown in Figure 7, the removal mechanism of Cr was investigated by XPS analysis, the appearance of a Cr2p peak on the used PEG@PTHA revealed that the Cr was successfully captured. According to the Cr2p enlarged spectrogram, the peaks at $588.6 \mathrm{eV}$ and $577.1 \mathrm{eV}$ were attributed to $\mathrm{Cr}(\mathrm{III})$, while the peaks located in $587.3 \mathrm{eV}$ and $579.2 \mathrm{eV}$ were assigned to $\mathrm{Cr}(\mathrm{VI})$. The most of toxic $\mathrm{Cr}(\mathrm{VI})$ was reduced to the weakly toxic $\mathrm{Cr}(\mathrm{III})$ due to the existence of the-OH group, and the $\mathrm{Cr}(\mathrm{III})$ was chelated on the PEG@PTHA during the adsorption-reduction process. Comparing with the other kinds of adsorbents in Table 4, the PEG@PTHA in this work possesses a higher adsorption amount and a brighter future for wastewater treatment.
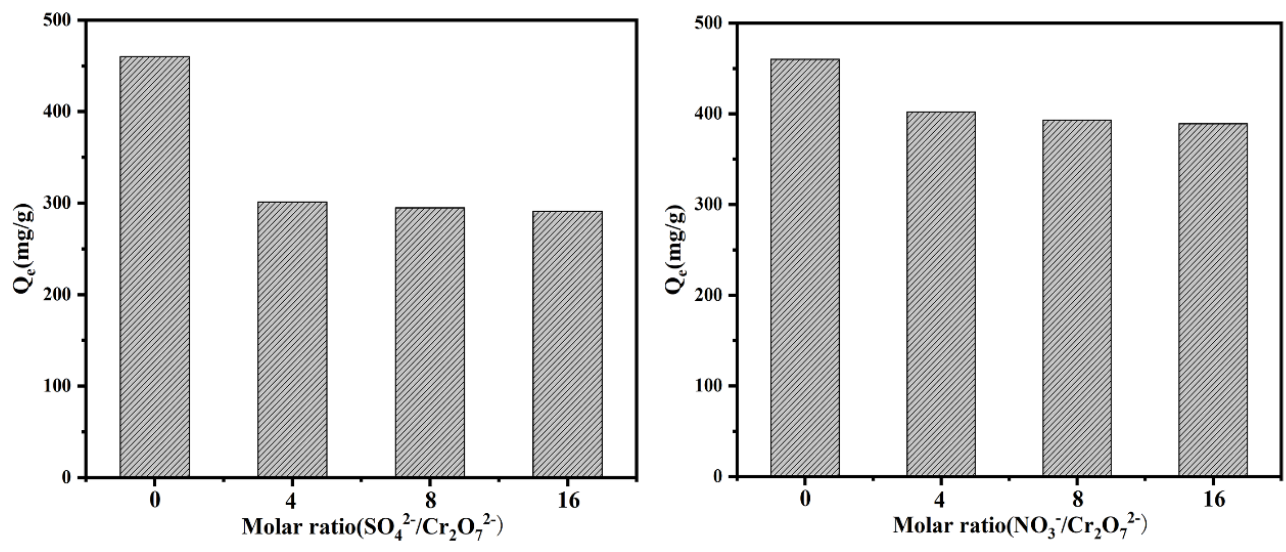

Figure 6. The effect of competing ions on the removal behavior towards $\mathrm{Cr}(\mathrm{VI})$.
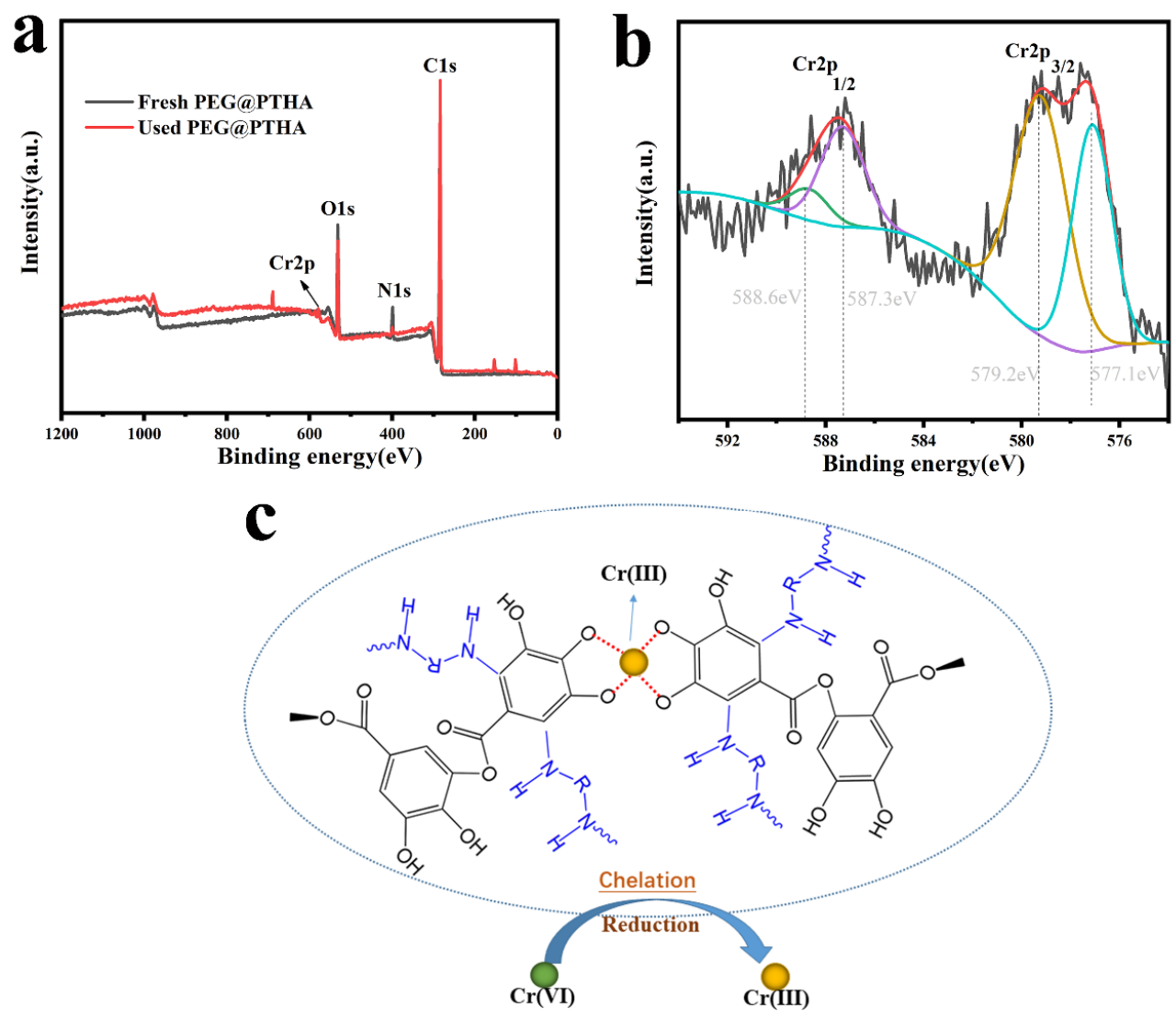

Figure 7. (a) the XPS analysis of fresh PEG@PTHA and used PEG@PTHA, (b) XPS Cr2p spectrogram on the used PEG@PTHA, (c) conjectural mechanism of adsorption. 
Table 4. Comparison of adsorption capacity with other adsorbents from previous studies.

\begin{tabular}{|c|c|c|}
\hline Adsorbent & Adsorption Capacity & Reference \\
\hline lignin-graphene oxide composite nanospheres & $154 \mathrm{mg} / \mathrm{g}$ & [22] \\
\hline two-dimensional (2D) Ti3C2Tx MXene nanosheets & $104 \mathrm{mg} / \mathrm{g}$ & [23] \\
\hline functionalized tannin-chitosan bentonite composite & $197 \mathrm{mg} / \mathrm{g}$ & [24] \\
\hline Nitrogen-Doped Carboxylated Porous Carbon & $104 \mathrm{mg} / \mathrm{g}$ & [25] \\
\hline
\end{tabular}

\section{Conclusions}

In this work, a PEG@PTHA adsorbent microsphere with a rough surface was fabricated successfully and used as an adsorbent for $\mathrm{Cr}(\mathrm{VI})$-wastewater treatment. Comparing with other kinds of adsorbents(Table 4), it possessed an approximate $99 \%$ removal rate at a low initial concentration (100 mg/L) and maximum adsorption capacity $(450 \mathrm{mg} / \mathrm{g})$, moreover, its adsorption capacity could reach up to $300 \mathrm{mg} / \mathrm{g}$ within $10 \mathrm{~min}$. The adsorption process better fitted with the pseudo-second-order model and Langmuir isotherm. There was not only physical adsorption but also chemical adsorption, virulent $\mathrm{Cr}(\mathrm{VI})$ was reduced to the less harmful $\mathrm{Cr}$ (III) during the adsorption process, and PEG@PTHA appears to have a high-efficiency $\mathrm{Cr}(\mathrm{VI})$ competitive adsorption against anions $\left(\mathrm{NO}_{3}{ }^{-}\right.$ and $\mathrm{SO}_{4}{ }^{2-}$ ). It can be concluded that the PEG@PTHA adsorbent with advantages of facile preparation, high selectivity, and low cost possesses excellent prospects in $\mathrm{Cr}(\mathrm{VI})$-contained wastewater treatment.

Author Contributions: Conceptualization, C.Y. and Q.L.; methodology, C.Y. and Y.Z.; validation, Q.L, Y.Z.; formal analysis, C.Y.; data curation, C.Y. and J.Y.; writing-original draft preparation, C.Y.; writing-review and editing, Q.L.; funding acquisition, F.-G.K. and Q.L. All authors have read and agreed to the published version of the manuscript.

Funding: This work is supported by the Key Research and Development Program of Shandong Province (2019GGX102027), and the Foundation (No. ZZ20190113) of State Key Laboratory of Biobased Material and Green Papermaking.

Institutional Review Board Statement: Not applicable.

Informed Consent Statement: Not applicable.

Data Availability Statement: Data sharing is not applicable.

Conflicts of Interest: All authors declare that they have no conflict of interest.

\section{References}

1. Ingelido, A.M.; Abballe, A.; Gemma, S.; Dellattea, E.; Iacovellaa, N.; De Angelisa, G.; Marraa, V.; Russob, F.; Vazzolerc, M.; Testai, E. Serum Concentrations of Perfluorinated Alkyl Substances in Farmers Living in Areas Affected by Water Contamination in the Veneto Region (Northern Italy). Environ. Int. 2020, 136, 105435. [CrossRef] [PubMed]

2. Jeon, C. Removal of $\mathrm{Cr}(\mathrm{VI})$ from Aqueous Solution Using Amine-impregnated Crab Shells in the Batch Process. J. Ind. Eng. Chem. 2019, 77, 111. [CrossRef]

3. Wang, J.L.; Chen, H. Catalytic Ozonation for Water and Wastewater Treatment: Recent Advances and Perspective. Sci. Total Environ. 2020, 704, 135249. [CrossRef] [PubMed]

4. Basu, A.; Behera, S.S.; Dash, S.; Banerjee, S.; Sarkaret, S.; Mohanty, C.K.; Dhal, N.K.; Parhi, P.K.; Tripathy, S.K. A Study on Removal of $\mathrm{Cr}$ (III) from Aqueous Solution Using Biomass of Cymbopogon Flexuosus Immobilized in Sodium Alginate Beads and Its Use as Hydrogenation Catalyst. J. Taiwan Inst. Chem. Eng. 2019, 102, 118. [CrossRef]

5. Ma, W.; Gao, J.; Chen, Z.; Hu, J.; Xin, G.; Pan, Y.; Zhang, Z.; Tan, D. A New Method of Cr(VI) Reduction Using SiC Doped Carbon Electrode and Cr(III) Recovery by Hydrothermal Precipitation. Colloids Surf. A Physicochem. Eng. Asp. 2021, 610, 125724. [CrossRef]

6. Wang, S.; Zhao, X.; Muhammad Adeel Sharif, H.; Chen, Z.; Chen, Y.; Zhou, B.; Xiao, K.; Yang, B.; Duan, Q. Amine-CdS for Exfoliating and Distributing Bulk MoO3 for Photocatalytic Hydrogen Evolution and Cr(VI) Reduction. Chem. Eng. J. 2021, 406, 126849. [CrossRef]

7. Yu, P.; Fu, F.; Sun, G.; Tang, B. Effects of Oxalate and Citrate on the Behavior and Redistribution of Cr(VI) During FerrihydriteCr(VI) co-precipitates Transformation. Chemosphere 2021, 266, 128977. [CrossRef] 
8. He, P.; Zhu, J.; Chen, Y.; Chen, F.; Zhu, J.; Liu, M.; Zhang, K.; Ganet, M. Pyrite-activated Persulfate for Simultaneous 2,4-DCP Oxidation and Cr(VI) Reduction. Chem. Eng. J. 2021, 406, 126758. [CrossRef]

9. Ngah, W.W.; Teong, L.C.; Hanafiah, M.M. Adsorption of Dyes and Heavy Metal Ions by Chitosan Composites: A Review. Carbohydr. Polym. 2011, 83, 1446. [CrossRef]

10. Saravanan, A.; Kumar, P.S.; Govarthanan, M.; George, C.S.; Vaishnavi, S.; Moulishwaran, B.; Praveen Kumara, S.; Jeevananthama, S.; Yaashikaa, P.R. Adsorption Characteristics of Magnetic Nanoparticles Coated Mixed Fungal Biomass for Toxic Cr(VI) Ions in Aquatic Environment. Chemosphere 2021, 267, 129226. [CrossRef]

11. Do Nascimento, B.F.; de Araujo, C.M.B.; do Nascimento, A.C.; da Silva, F.L.H.; de Melo, D.J.N.; Jaguaribe, E.F.; Cavalcanti, J.V.F.L.; da Motta Sobrinhoet, M.A. Detoxification of Sisal Bagasse Hydrolysate Using Activated Carbon Produced from the Gasification of Açaí Waste. J. Hazard. Mater. 2021, 409, 124494. [CrossRef]

12. Bao, S.; Yang, W.; Wang, Y.; Yu, Y.; Sun, Y. Highly Efficient and Ultrafast Removal of Cr(VI)in Aqueous Solution to ppb Level by Poly(allylamine hydrochloride) Covalently Cross-linked Amino-modified Graphene Oxide. J. Hazard. Mater. $2021,409,124470$. [CrossRef] [PubMed]

13. Wang, Z.; Kang, S.B.; Won, S.W. Selective Adsorption of Palladium(II) from Aqueous Solution Using Epichlorohydrin Crosslinked Polyethylenimine-chitin Adsorbent: Batch and Column Studies. J. Environ. Chem. Eng. 2021, 9, 9. [CrossRef]

14. Luo, Q.; Huang, X.; Luo, Y.; Yuan, H.; Ren, T.; Li, X.; Xu, D.; Guo, X.; Wu, Y. Fluorescent Chitosan-based Hydrogel Incorporating Titanate and Cellulose Nanofibers Modified with Carbon Dots for Adsorption and Detection of Cr(VI). Chem. Eng. J. 2021, 407, 127050. [CrossRef]

15. Hazer, B.; Ashby, R.D. Synthesis of a Novel Tannic Acid-functionalized Polypropylene as Antioxidant Active-packaging Materials. Food Chem. 2021, 344, 128644. [CrossRef] [PubMed]

16. Hu, T.; Liu, Q.; Gao, T.; Dong, K.; Wei, G.; Yao, J. Facile Preparation of Tannic Acid-Poly(vinyl alcohol)/Sodium Alginate Hydrogel Beads for Methylene Blue Removal from Simulated Solution. ACS Omega 2018, 3, 7523. [CrossRef]

17. Gao, S.; Liu, Q.; Liu, Q.; Yuan, C.; Gao, T.; Yao, J. Facile Synthesis of Hollow Globular Cr(VI)-adsorbents Inspired from Assembly to Polymerization. J. Clean. Prod. 2020, 250, 119485. [CrossRef]

18. Liu, Q.; Liu, Q.; Liu, B.; Hu, T.; Liu, W.; Yao, J. Green Synthesis of Tannin-hexamethylendiamine Based Adsorbents for Efficient Removal of Cr(VI). J. Hazard. Mater. 2018, 352, 27. [CrossRef] [PubMed]

19. Janani, B.; Al-Mohaimeed, A.M.; Raju, L.L.; Al Farraj, D.A.; Thomas, A.M.; Khan, S.S. Synthesis and Characterizations of Hybrid PEG-Fe3O4 Nanoparticles for the Efficient Adsorptive Removal of Dye and Antibacterial, and Antibiofilm Applications. J. Environ. Health Sci. Eng. 2021. [CrossRef]

20. Lee, H.; Dellatore, S.M.; Miller, W.M.; Messersmith, P.B. Mussel-inspired Surface Chemistry for Multifunctional Coatings. Science 2007, 318, 426. [CrossRef] [PubMed]

21. Hu, T.; Liu, Q.; Liu, Q.; Wu, Y.; Qiao, C.; Yao, J. Toxic Cr removal from Aqueous Media Using Catechol-amine Copolymer Coating Onto As-prepared Cellulose Carbohydrate. Polymers 2019, 209, 291.

22. Yan, Z.; Wu, T.; Fang, G.; Ran, M.; Shen, K.; Liao, G. Self-assembly Preparation of Lignin-graphene Oxide Composite Nanospheres for Highly Efficient Cr(vi) Removal. RSC Adv. 2021, 11, 4713. [CrossRef]

23. Karthikeyan, P.; Ramkumar, K.; Pandi, K.; Fayyaz, A.; Meenakshi, S.; Park, C.M. Effective Removal of Cr(VI) and Methyl Orange from the Aqueous Environment Using Two-dimensional (2D) Ti3C2Tx MXene Nanosheets. Ceram. Int. 2021, 47, 3692. [CrossRef]

24. Li, Z.; Zou, P.; Yang, J.; Huang, M.; Zhang, L.; Huang, C.; Yang, F.; Huang, R.; Lv, S.; Wei, G. A Functionalized Tannin-chitosan Bentonite Composite with Superior Adsorption Capacity for Cr (VI). J. Polym. Eng. 2021, 41, 34. [CrossRef]

25. Bakry, A.M.; Awad, F.S.; Bobb, J.A.; El-Shall, M.S. Multifunctional Binding Sites on Nitrogen-Doped Carboxylated Porous Carbon for Highly Efficient Adsorption of Pb(II), Hg(II), and Cr(VI) Ions. ACS Omega 2020, 5, 33090. [CrossRef] [PubMed] 